\title{
Algorithm for Determining the Knock Resistance of Pipeline Natural Gases
}

\author{
Sander Gersen ${ }^{1,}$, , Martijn van Essen ${ }^{1}$, Gerco van Dijk ${ }^{1}$, Howard Levinsky ${ }^{1,2}$ \\ ${ }^{1}$ DNV-GL Oil \& Gas, Groningen, The Netherlands \\ ${ }^{2}$ Energy and Sustainability Research Institute, University of Groningen, Groningen, The Netherlands
}

Email address:

Sander.Gersen@dnvgl.com (S. Gersen)

${ }^{*}$ Corresponding author

To cite this article:

Sander Gersen, Martijn van Essen, Gerco van Dijk, Howard Levinsky. Algorithm for Determining the Knock Resistance of Pipeline Natural Gases. International Journal of Energy and Power Engineering. Vol. 9, No. 4, 2020, pp. 41-48. doi: 10.11648/j.ijepe.20200904.11

Received: July 15, 2020; Accepted: August 18, 2020; Published: September 3, 2020

\begin{abstract}
A next-generation algorithm to calculate the PKI methane number is reported. The algorithm is suitable for a wide range of fuel compositions encountered in natural gas pipelines, including admixture of hydrogen and carbon monoxide from renewable sources. Comparison with measurements of knock in a commercial engine shows that the algorithm allows sharp distinction between fuel compositions that do or do not cause engine knock under given operating conditions. Moreover, the algorithm presented here demonstrates superior performance as compared to the existing methods from MWM and AVL. The methane numbers calculated using the PKI MN algorithm for a wide range of fuel compositions are within the uncertainty of the experimental knock measurements. In contrast, methods that are currently used do not predict the knock behavior of the measured gas compositions reliably. A major benefit of the algorithm presented here is that it consists of a simple polynomial equation that can be easily integrated into real-time gas-quality sensing equipment to calculate the PKI MN for assessment of pipeline gas quality or into engine management systems to allow next-generation feed-forward, fuel-adaptive control. In contrast, the current methods such as AVL and MWM need dedicated (and for AVL, proprietary) solvers that iteratively calculate the methane number. Furthermore, given the experimentally verified reliability and ease of implementation of the PKI MN algorithm, we assert that it is an excellent, open-source candidate for international standards for specifying the knock resistance of gaseous fuels.
\end{abstract}

Keywords: Pipeline Gas, Natural Gas, Methane Number, Engine Knock, Algorithm

\section{Introduction}

The globalization of the natural gas market and the drive towards sustainability are increasing the diversity of the supply of gases to the natural gas infrastructure. For example, the introduction of regasified LNG can result in higher fractions of non-methane hydrocarbons in the natural gas grid than the traditionally distributed pipeline gases for which these hydrocarbons have been removed during processing. Also, the growing interest in the introduction of sustainable fuels such as hydrogen and gases derived from biomass results in the introduction of "new" gas compositions, having components that do not occur in the traditional natural gas supply. Consequently, the increasing variations in gas composition influence the so-called knock resistance of the fuel [1]. For the optimal and safe operation of gas engines, it is of great importance to characterize the knock resistance of gases accurately. Knock phenomena are caused by autoignition of unburned fuel mixture, the so-called end gas, in the cylinder before the mixture is completely consumed by the propagating flame [1]. Mild engine knock increases pollutant emissions, while severe knock can cause engine failure or physically damage the engine, and should thus be avoided. To ensure that gas engines are matched with the expected variations in fuel composition, the knock resistance of the fuel must be characterized, and subsequently specified, unambiguously.

Traditional methods for characterizing the knock resistance of gaseous fuels, such as the methane number developed by AVL [2], compare the knock propensity of a given fuel with an equivalent methane/hydrogen mixture. 
The AVL methane number was developed in the 1960s and was the first algorithm developed. Several other methane number tools have been developed since then [2-17] and some of them use the data from the original experimental work performed by AVL. An example is the MWM method, published in the standard EN 16726, 2015 [7], which is based on the same data set and methodology as AVL [2], but adapted for lean-burn engines [9]. However, MWM extended the range of hydrocarbons up to $3 \%$ of each component of $\mathrm{C} 5, \mathrm{C} 6$ and $\mathrm{C} 7$, while the effect of nitrogen (supposed to be negligible for lean-burn engines) has also been adjusted [9]. The AVL data was generated using engine technology typical for the 1960s, which had significantly different in-cylinder conditions than modern engines; this can result in a different ranking of the knock resistance [18]. Moreover, the majority of the MN methods, including AVL and MWM do not differentiate between isomers of higher hydrocarbons while these isomers have demonstrably different knock resistance [17, 18]. Another shortcoming is that most of the existing methane number methods are based on complex iterative relations to find the methane number for a given gas composition, which complicates the integration of these methods into gas-analysis equipment, such as real-time gas sensors. Such equipment is used in natural gas grids or fuel-adaptive engine control systems requiring real-time determination of the knock resistance of the fuel [19, 20].

Recently, a new algorithm for determining the knock resistance of LNG compositions was developed and successfully tested using knock data generated on a lean-burn spark-ignited engine [21]. The algorithm is based on the Propane Knock Index Methane Number (PKI MN) [18]. The algorithm is a polynomial equation and is therefore easy to implement into real-time measurement and control systems. In contrast to the existing empirically derived algorithms, the PKI MN algorithm is based on the combustion properties of the fuel mixtures for modern engines. In this work, we extend the algorithm to consider (sustainable) gas compositions that are transported in the natural gas grid and demonstrate a next-generation, open source, easy-to-implement algorithm to calculate the methane number of natural gas pipeline compositions.

As argued in [18-21], an accurate algorithm to calculate the knock resistance safeguards the end user by ensuring that engine performance is not unnecessarily compromised (for example, by derating) or is unnecessarily at risk. It also ensures that gases are not excluded from the market, or "overtreated" to remove knock-enhancing components without cause.

\section{Approach}

The approach is described in detail in [21] and is summarized briefly here. The gas-input-only algorithm is based on simulations using a two-zone numerical model that simulates engine processes governing knock when varying the fuel composition [18]. The model was developed to quantify the knock resistance of pipeline gases for a lean-burn, spark-ignited CHP engine, whose operating condition is presented in Table 1.

Table 1. Specifications test engine [18].

\begin{tabular}{|c|c|}
\hline Engine make \& type & MAN E2876LE302 \\
\hline Engine configuration & $\begin{array}{l}6 \text { cylinder in-line } \\
\text { turbocharged } \\
\text { intercooled }\end{array}$ \\
\hline $\begin{array}{l}\text { Combustion system \& combustion } \\
\text { stoichiometry }\end{array}$ & $\begin{array}{l}\text { mono-gas } \\
\text { open chamber } \\
\text { lean-burn ( } \lambda=1.55\end{array}$ \\
\hline $\begin{array}{l}\text { Rated power \& speed } \\
\text { (corresponding BMEP) }\end{array}$ & $\begin{array}{l}208 \mathrm{~kW} \text { at } 1500 \mathrm{rpm} \\
(13.0 \mathrm{bar})\end{array}$ \\
\hline Bore x Stroke & $128 \times 166 \mathrm{~mm}$ \\
\hline Compression ratio & $11.0: 1$ \\
\hline Excess air ratio, $\lambda$ & 1.55 \\
\hline Intake temperature, ${ }^{\circ} \mathrm{C}$ & 64 \\
\hline
\end{tabular}

The model predicts engine knock by computing the autoignition process by considering the compression and burn period of the engine cycle. The model uses as input all relevant engine parameters such as geometry, operating conditions, combustion air humidity and gas composition and calculates the knock resistance of a given gaseous fuel. The knock resistance of different gases are ranked on a methane/propane-based scale [18], i.e., the knock resistance for a given fuel mixture is expressed as an equivalent fraction of propane in methane under the same engine conditions. The veracity of the knock model was demonstrated [18] by comparing the predictions of autoignition of the end gas using the model for a wide variety of fuel compositions, including admixtures of $\mathrm{C}_{2} \mathrm{H}_{6}, \mathrm{C}_{3} \mathrm{H}_{8}, \mathrm{i}-\mathrm{C}_{4} \mathrm{H}_{10}, \mathrm{n}-\mathrm{C}_{4} \mathrm{H}_{10}, \mathrm{H}_{2}, \mathrm{CO}$ and $\mathrm{CO}_{2}$ in natural gas. As an illustration, we replot the measurements and computations relevant for characterizing the range gas compositions transported in natural gas grids. As can be seen in Figure 1 and shown in Ref. [18], the measurements and computations of knock resistance are in agreement within the uncertainty of the measurements $\left( \pm 0.75^{\circ} \mathrm{CA}\right)$.

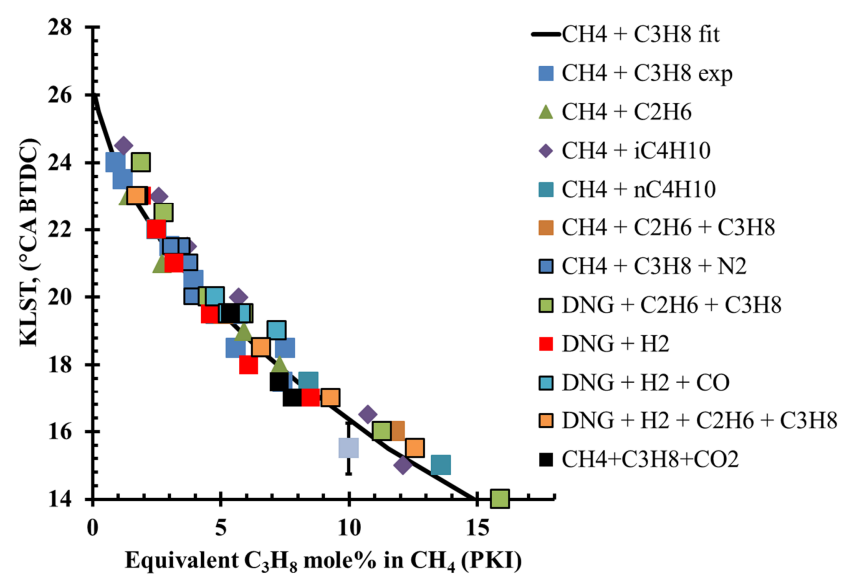

Figure 1. Calculated knock resistance (PKI) versus measured knock resistance (KLST).

\section{Algorithm Development for Pipeline Gases}

To generate data for the gas-input-only algorithm we 
performed several thousand simulations using the knock model using the engine conditions shown in Table 1 and by assuming a relative combustion air humidity of $0 \%$. As discussed above, the knock model calculates the PKI (propane percentage in methane) for the corresponding gas composition. The range of fuel composition used in simulations are presented in Table 2, which corresponds to a PKI MN ranging from 100 to 53. This covers the range of typical natural gas compositions distributed and includes fractions of $\mathrm{H}_{2}, \mathrm{CO}, \mathrm{CO}_{2}, \mathrm{C}_{6}+$ and $\mathrm{H}_{2} \mathrm{~S}$ that can arise from the admixture of renewable gases to natural gas. The simulations have been performed for binary and multicomponent gas mixtures. We note in passing that the inclusion of these components is a significant extension of the algorithm reported in [21]; all binary and multicomponent mixtures with the new components must be simulated and included in the fit routine described below.

Table 2. Range of gas compositions used for the test.

\begin{tabular}{lll}
\hline Species & Min, mole\% & Max, mole\% \\
\hline $\mathrm{CH}_{4}$ & 70 & 100 \\
$\mathrm{C}_{2} \mathrm{H}_{6}$ & 0 & 20 \\
$\mathrm{C}_{3} \mathrm{H}_{8}$ & 0 & 20 \\
$\mathrm{i}-\mathrm{C}_{4} \mathrm{H}_{10}$ & 0 & 5 \\
$n-\mathrm{C}_{4} \mathrm{H}_{10}$ & 0 & 5 \\
$n-\mathrm{C}_{5} \mathrm{H}_{12}$ & 0 & 2 \\
$\mathrm{i}-\mathrm{C}_{5} \mathrm{H}_{12}$ & 0 & 2 \\
$n \mathrm{neo}-\mathrm{C}_{5} \mathrm{H}_{12}$ & 0 & 2 \\
$\mathrm{C}_{6}+$ & 0 & 1.5 \\
$\mathrm{CO}$ & 0 & 10 \\
$\mathrm{CO}$ & 0 & 20 \\
$\mathrm{~N}_{2}$ & 0 & 20 \\
$\mathrm{H}_{2}$ & 0 & 20 \\
$\mathrm{H}_{2} \mathrm{~S}$ & 0 & 0.5 \\
\hline
\end{tabular}

To develop the gas-input-only algorithm a least square regression analyses was performed on the simulated PKI values for the for binary and multicomponent gas compositions. As described in [21], a polynomial equation calculates the PKI value from the mole fractions of the individual components of the fuel mixture;

$$
P K I=\sum \alpha_{i} X_{i}^{n}+\sum \beta_{i_{* j} m} X_{i}^{n} X_{j}^{m},
$$

where $\mathrm{X}$ is the mole fraction, $\mathrm{i}, \mathrm{j}=\mathrm{CH}_{4}, \mathrm{C}_{2} \mathrm{H}_{6}, \mathrm{C}_{3} \mathrm{H}_{8}, \mathrm{i}-\mathrm{C}_{4} \mathrm{H}_{10}$, n- $\mathrm{C}_{4} \mathrm{H}_{10}, \mathrm{n}-\mathrm{C}_{5} \mathrm{H}_{12}, \mathrm{i}-\mathrm{C}_{5} \mathrm{H}_{12}$, neo- $\mathrm{C}_{5} \mathrm{H}_{12}, \mathrm{H}_{2}, \mathrm{CO}, \mathrm{CO}_{2}$ and $\mathrm{N}_{2}$ with $\mathrm{i} \neq \mathrm{j}, \mathrm{n}=1-4$ and $\mathrm{m}=1,2$. The coefficients $\alpha$ and $\beta$ of the polynomial were determined from the best fit to the PKI values from the test matrix. The coefficients are given in the Appendix. To account for the presence of $\mathrm{C}_{6}+$ and $\mathrm{H}_{2} \mathrm{~S}$ in the gas mixture, scaling factors are derived based on autoignition measurements in a rapid compression machine [22]. These scaling factors are used in the algorithm to translate the effect of $\mathrm{C}_{6}+$ and $\mathrm{H}_{2} \mathrm{~S}$ on the knock resistance of a gas mixture to an equivalent fraction of $n-C_{5} H_{12}$. The factors are used to correct the methane and n-pentane mole fractions as follows:

$$
\begin{gathered}
X_{C H 4, \text { new }}=X_{C H 4 \text { in gasmixture }}-0.3 \times X_{C 6+} \\
X_{n C 5 H 12, \text { new }}=X_{n C 5 H 12 \text { in gasmixture }}+X_{H 2 S}+1.3 \times X_{C 6+}
\end{gathered}
$$

Where $\mathrm{X}$ denotes the mole fraction. Here we note that the results of the algorithm are only valid if the total mole percentages of the gas mixture is $100 \%$.

Traditional methane number(s) use a methane-hydrogen scale, with 100 having the knock equivalent of pure methane, and 0 being nominally assigned to hydrogen. The methane-propane based scale (PKI) derived here has pure methane as 0 and with an increasing value with the equivalent propane content. Given the convenience of a 0-100 scale, as described previously [21] we convert the PKI data by fitting the sixth-order polynomial shown in Equation (4), below, to generate the PKI Methane Number.

$$
\text { PKI MN }=\mathrm{a} 1 \times \mathrm{PKI}+\mathrm{a} 2 \times \mathrm{PKI}^{2}+\mathrm{a} 3 \times \mathrm{PKI}^{3}+\mathrm{a} 4 \times \mathrm{PKI}^{4}+\mathrm{a} 5 \times \mathrm{PKI}^{5}+\mathrm{a} 6 \times \mathrm{PKI}^{6}+\mathrm{b}
$$

Table 3. Coefficients in equation (4) for conversion of PKI to PKI MN [21].

\begin{tabular}{ll}
\hline Coefficient & Values \\
\hline a1 & -9.757977 \\
a2 & 1.484961 \\
a3 & -0.139533 \\
a4 & $7.031306 \times 10-3$ \\
a5 & $-1.770029 \times 10-4$ \\
a6 & $1.751212 \times 10-6$ \\
b & 100 \\
\hline
\end{tabular}

In Figure 2 the PKI MN calculated by using the knock model is plotted versus the PKI MN calculated by using the algorithm (equations 1-4). From Figure 2 it can be seen that the predictions of the gas-input-only algorithm are in excellent agreement with the PKI MN values derived from the knock model: the average deviation between the model results and the algorithm predictions is 0.25 points, while the maximum difference is approximately 1.5 points.

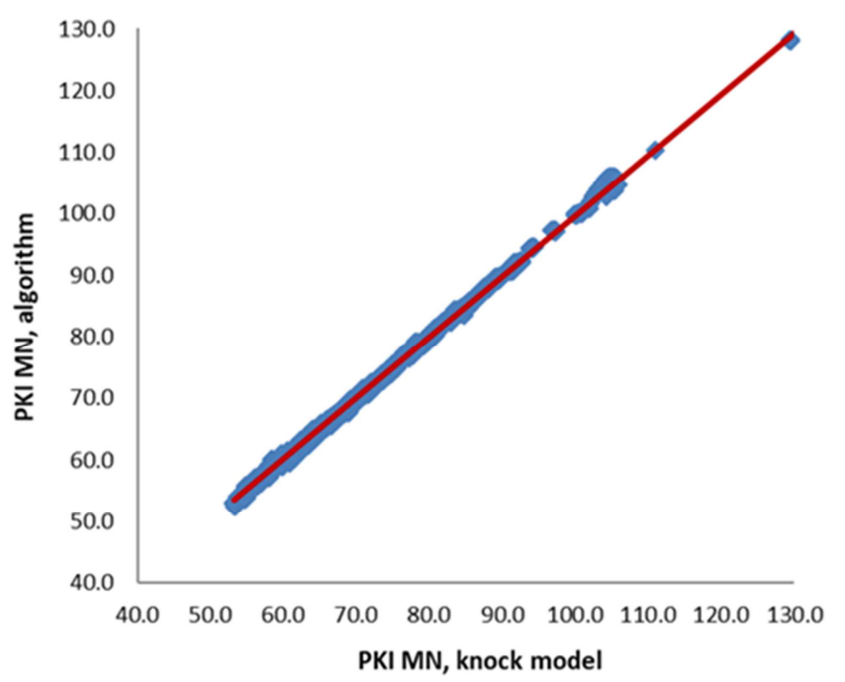

Figure 2. PKI MN calculated by using the knock model versus the PKI MN calculated by using the algorithm (equations 1-4). 
Following [21], to assess the accuracy of the new algorithm, the PKI MN for the fuel compositions measured in the engine were calculated with the algorithm and compared with the measured knock resistance (KLST). Figure 3 shows the result. Here we recall that, in principle, two compositions having the same KLST have the same experimental knock resistance. The average spread at constant KLST using the PKI MN algorithm is about \pm 1.5 points, with a maximum spread of \pm 4.5 points. Compared to the comparison given in [18], which showed model predictions within the experimental uncertainty in KLST, the spread here is due to the fact that the algorithm is computed using fixed engine conditions, while the KLST is determined at varying experimental conditions, such as air humidity and intake temperature, which can substantially impact the knock resistance, as discussed previously [23], and are included in the knock model [18]. We note the clustering of data, particularly regarding $\mathrm{H}_{2}$,, $\mathrm{CO}$ - and $\mathrm{CO}_{2}$-containing mixtures, attesting to the veracity of the algorithm.

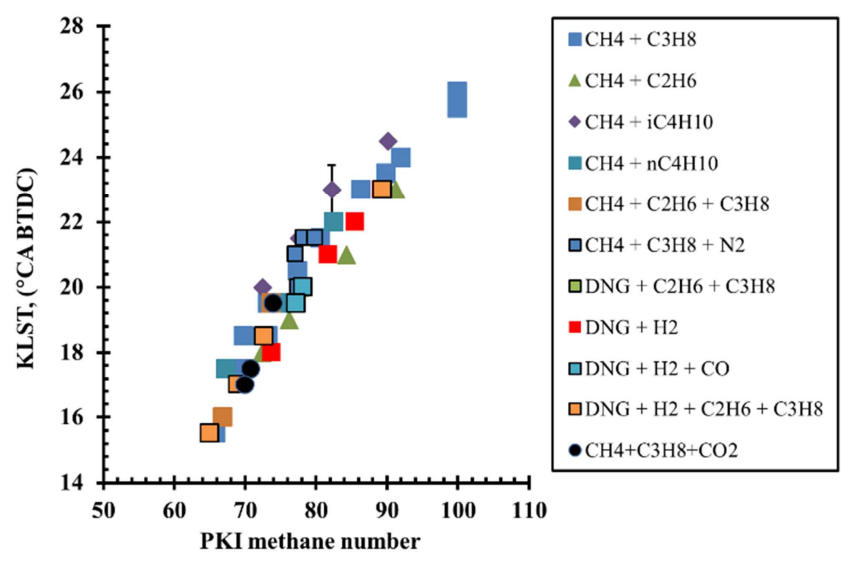

Figure 3. Experimentally determined knock resistance (KLST) versus PKI $M N$ calculated by the algorithm. The vertical error bar denotes the uncertainty in measured KLST of $\pm 0.75^{\circ} \mathrm{CA}$.

\section{Comparison KLST Experiments with MWM and AVL Methods}

To compare the performance of the AVL and MWM methane numbers with the PKI MN the measured knock resistance (KLST) is plotted as function of the knock resistance calculated by the AVL and MWM methods for the gas compositions examined in the gas engine, as done in [21] for LNG compositions. In contrast to the results shown in Figure 3, Figure 4 shows that the methane number calculated using AVL gives a substantially larger spread; the maximum deviation in the AVL methane number at constant KLST is about \pm 7.5 points. As is well known, $\mathrm{n}-\mathrm{C}_{4} \mathrm{H}_{10}$ and $\mathrm{i}-\mathrm{C}_{4} \mathrm{H}_{10}$ are both treated as $n-\mathrm{C}_{4} \mathrm{H}_{10}$ in the AVL algorithm. As a result, the knock resistance of the $\mathrm{i}-\mathrm{C}_{4} \mathrm{H}_{10}$-containing mixtures is systematically underpredicted, while for the $n-\mathrm{C}_{4} \mathrm{H}_{10}$ containing mixtures the knock resistance is overpredicted. Furthermore, the $\mathrm{CO}_{2}$-containing mixtures are shifted to the right-hand side of the figure indicating that the calculated methane numbers are systematically too high for the lean-burn engine used here (Table 1).

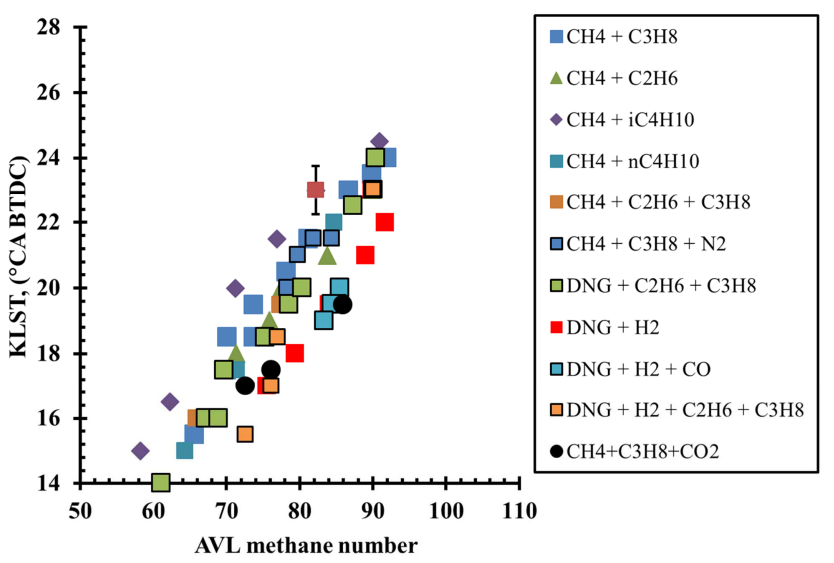

Figure 4. Experimentally determined knock resistance (KLST) versus AVL $M N$ method. The vertical error bar denotes the uncertainty in measured KLST of $\pm 0.75^{\circ} \mathrm{CA}$.

Comparison between the measured KLST and the calculated methane number using the MWM method, presented in Figure 5 , shows a maximum spread at constant KLST of \pm 7 MWM $\mathrm{MN}$. The larger spread in comparison with the PKI $\mathrm{MN}$ is caused by the large overprediction of $\mathrm{CO}_{2}$. Furthermore, the MWM method also does not make a distinction between i$\mathrm{C}_{4} \mathrm{H}_{10}$ and $\mathrm{n}-\mathrm{C}_{4} \mathrm{H}_{10}$; as a result, the knock resistance of $\mathrm{n}-\mathrm{C}_{4} \mathrm{H}_{10}$ seems to be overpredicted and that of $\mathrm{i}-\mathrm{C}_{4} \mathrm{H}_{10}$ underpredicted. Moreover, the MWM method is not sensitive for $\mathrm{N}_{2}$ and $\mathrm{CO}$; increasing the fractions of $\mathrm{CO}$ and $\mathrm{N}_{2}$ does not affect the methane number, in contract to what is observed in the measurements and captured by the PKI method.

As also observed for LNG compositions [21], an interesting observation is that MWM differs substantially from AVL even for hydrocarbon mixtures without nitrogen and hydrogen for which MWM was optimized. Whether this discrepancy is accidental or intentional, the absence of experimental data verifying the adequacy of the MWM algorithm (as compared to AVL) clouds the range of applicability of the method.

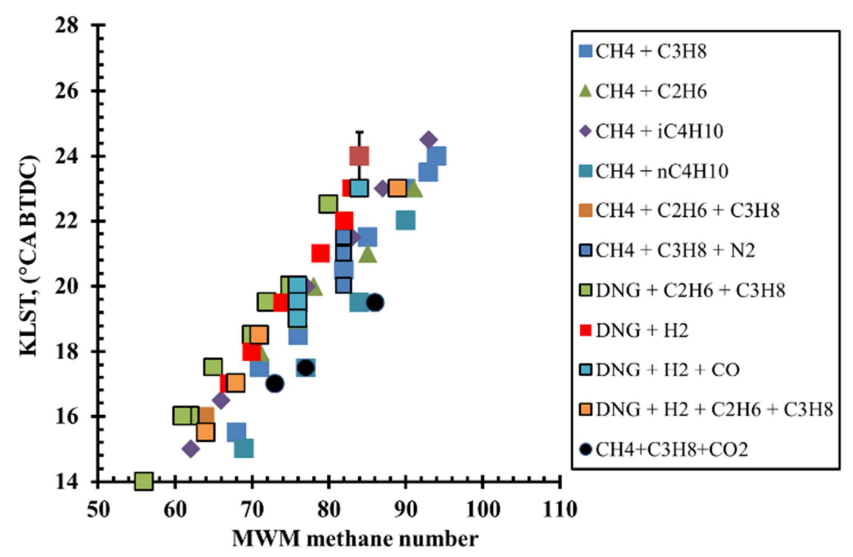

Figure 5. Experimentally determined knock resistance (KLST) versus MWM $M N$ method. The vertical error bar denotes the uncertainty in measured KLST of $\pm 0.75^{\circ} \mathrm{CA}$. 


\section{Variation in Methane Numbers Using Different Methods for "Pipeline" Gases}

To investigate the extent to which the methane number for "pipeline" gases can differ among different methane numbers methods, we defined 15 gas compositions and calculated their methane number using the PKI MN, MWM MN and the AVL MN methods. The compositions are given in Table 4. A number of the compositions selected represent typical natural gas compositions while others, containing high fractions of $\mathrm{CO}_{2}, \mathrm{H}_{2}$ and $\mathrm{CO}$, are included to anticipate the admixture of renewable gases in the gas grid. The results presented in Table 4 show that the calculations using the three methane number methods give similar results for the majority of the 'typical' pipeline gases (gases 1-7), with the maximum observed deviation being 3 points for these gases. As observed in the measurements presented in Figures 3-5, large differences between the PKI MN, on the one hand, and both the MWM NM and AVL MN, on the other hand, is observed for gas compositions with large fractions of $\mathrm{CO}_{2}$ (gases 8-10); for example, the methane number for gas 9, containing $16 \% \mathrm{CO}_{2}$ is 75 when using the PKI MN algorithm while the MWM and AVL methods both predict a methane number of 86. It is not surprising that the MWM and AVL MN give similar methane numbers since these algorithms are based on the same data, as mentioned above. The difference between the PKI MN and AVL MN can be partially ascribed to the difference in air factor used in the engine for which the results are derived; AVL MN is based on a stoichiometric gas engine while the PK MN is derived for fuel-lean conditions. Furthermore, the PKI MN is derived from multicomponent mixtures containing $\mathrm{CO}_{2}$, while the AVL and MWM algorithms are based on the extrapolation of measurements performed with binary $\mathrm{CH}_{4}-\mathrm{CO}_{2}$ mixtures [2]. As described in [24] the knock response of multicomponent $\mathrm{CH}_{4} / \mathrm{C}_{\mathrm{x}} \mathrm{H}_{\mathrm{y}} / \mathrm{CO}_{2}$ mixtures differs from those of binary $\mathrm{CH}_{4} / \mathrm{CO}_{2}$ mixtures. We point out that overestimating the methane number when using AVL and $\mathrm{MWM}$ for $\mathrm{CO}_{2}$-containing gases can lead to unexpected risk for the end user.

We also observe that the AVL MN method can yield large uncertainty for mixtures containing hydrogen when compared to the PKI and MWM MNs. Increasing the fraction of hydrogen also increases the difference in calculated methane number between the PKI MN and MWM MN; the PKI MN is 57 for gas mixture 13 , containing $20 \%$ hydrogen while the MWM method calculates a methane number of 61 for the same mixture. As described in [21] for binary mixtures containing propane, large discrepancies occur when using the MWM method; for example, for gas 15 , containing $5 \%$ propane a methane number of 75 is calculated when using the AVL and PKI MN method while the MWM method calculates a substantial higher methane number of 80 . As also concluded in [21,24], caution is advised when considering such mixtures.

Table 4. Calculated methane numbers using the PKI MN, MWM MN [7] and AVL MN [2] method.

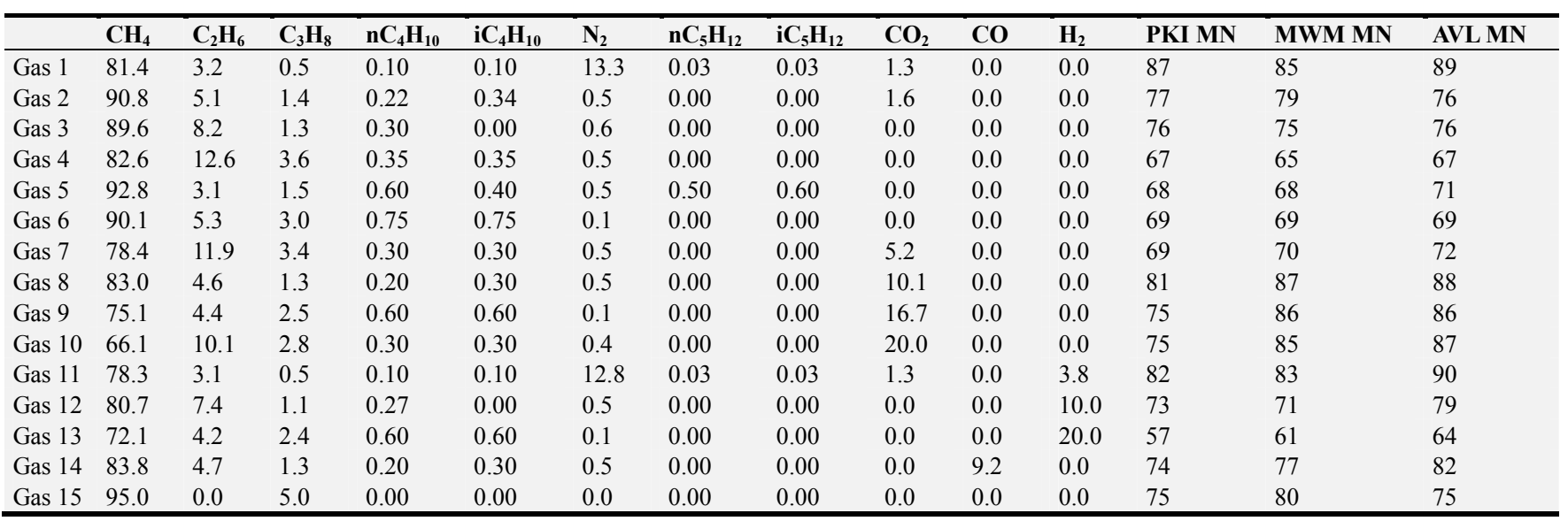

\section{Summary and Conclusions}

This paper describes the development of a next-generation algorithm to calculate the knock resistance of gaseous fuels using the Propane Knock Index Methane Number (PKI MN) for current- and future fuel compositions transported in natural gas grids. The algorithm has been derived using a polynomial regression analyses applied to thousands of knock simulations using a dedicated engine knock model developed for a lean-burn, medium-BMEP gas engine. The gas-input-only algorithm was found to reproduce faithfully the PKI MN calculated from the knock model used in the regression: the average deviation was only 0.25 points, while the maximum deviation observed is 1.5 points.

Comparison with knock measurements shows that the algorithm allows a sharp distinction between fuel compositions that do or do not cause engine knock under given operating conditions. Moreover, the algorithm developed here shows superior performance compared to the existing methods from MWM and AVL. For example, comparison between the measured KLST for the engine used in the verification and the calculated Methane Number using the different methods shows that the maximum deviation at constant KLST is \pm 7 for the MWM method, roughly \pm 7.5 when using AVL method and only \pm 4.5 when using the PKI $\mathrm{MN}$ algorithm. In addition to its accuracy, a major advantage to using the PKI method is that the Methane Number is 
directly and unambiguously coupled to methane/propane mixtures, allowing engine manufacturers to verify engine performance using these mixtures with certainty. Another benefit is that the algorithm consists of a simple polynomial equation that can be easily integrated into real-time gas-quality sensing equipment to calculate the PKI $\mathrm{MN}$ for pipeline gas quality assessment or into engine management systems to allow accurate feed-forward, fuel-adaptive control. In contrast, the current methods such as AVL and MWM need a dedicated (or for AVL proprietary) solver that iteratively calculate the methane number. Furthermore, given the experimentally verified reliability and ease of implementation of the PKI MN algorithm, we assert that it is an excellent, open-source candidate for international standards for specifying the knock resistance of gaseous fuels.

\section{Acknowledgements}

The authors gratefully acknowledge the N. V. Nederlandse Gasunie for financial support of the development of the algorithm for pipeline fuel compositions.

\section{Appendix: Measured Gas Compositions with Calculated Methane numbers}

$$
\begin{aligned}
& { }_{\text {Coefficient }} \\
& \alpha_{C_{4}} \\
& \alpha_{\left({ }_{\left(C H_{4}\right.}\right)^{2}} \\
& \alpha_{\left({ }_{\left(H_{4}\right.}\right)^{3}} \\
& \alpha_{\left({ }_{\left(C H_{4}\right.}\right)^{4}} \\
& \alpha_{C_{2} H_{6}} \\
& \alpha_{\left(C_{2} H_{6}\right)^{2}} \\
& \alpha_{\left(C_{2} H_{6}\right)^{3}} \\
& \alpha_{\left(C_{2} H_{6}\right)^{4}} \\
& \alpha_{C_{3} H_{8}} \\
& \alpha_{\left(C_{3} H_{8}\right)^{2}} \\
& \alpha_{\left(C_{3} H_{8}\right)^{3}} \\
& \alpha_{\left(C_{3} H_{8}\right)^{4}} \\
& \alpha_{n-C_{4} H_{10}} \\
& \alpha_{\left(n-C_{4} H_{10}\right)^{2}} \\
& \alpha_{\left(n-C_{4} H_{10}\right)^{3}} \\
& \alpha_{\left(n-C_{4} H_{10}\right)^{4}} \\
& \alpha_{i-C_{4} H_{10}} \\
& \alpha_{\left(i-C_{4} H_{10}\right)^{2}} \\
& \alpha_{\left(i-C_{4} H_{10}\right)^{3}} \\
& \alpha_{\left(i-C_{4} H_{10}\right)^{4}} \\
& { }_{(i n}
\end{aligned}
$$

Value

\begin{tabular}{|c|c|}
\hline Coefficient & Value \\
\hline$\alpha_{n-C_{5} H_{12}}$ & 2571.93079360535 \\
\hline$\alpha_{\left(n-C_{5} H_{12}\right)^{2}}$ & 10516.4941092275 \\
\hline$\alpha_{\left(n-C_{5} H_{12}\right)^{3}}$ & -770539.377197693 \\
\hline$\alpha_{\left(n-C_{5} H_{12}\right)^{4}}$ & 28633475.5865654 \\
\hline$\alpha_{i-C_{5} H_{12}}$ & -3582.96784435379 \\
\hline$\alpha_{\left(i-C_{5} H_{12}\right)^{2}}$ & 0 \\
\hline$\alpha_{\left(i-C_{5} H_{12}\right)^{3}}$ & 403155.950864334 \\
\hline$\alpha_{\left(i-C_{5} H_{12}\right)^{4}}$ & -11917333.8379329 \\
\hline$\alpha_{n e o-C_{5} H_{12}}$ & 1123.39636709865 \\
\hline$\alpha_{\left(\text {neo- }-C_{5} H_{12}\right)^{2}}$ & 1679.7280752481 \\
\hline$\alpha_{\left(n e o-C_{5} H_{12}\right)^{3}}$ & -172182.649067176 \\
\hline$\alpha_{\left(n e o-C_{5} H_{12}\right)^{4}}$ & 3467918.60746699 \\
\hline$\alpha_{N_{2}}$ & -469.428097827742 \\
\hline$\alpha_{\left(N_{2}\right)^{2}}$ & 352.688107288763 \\
\hline$\alpha_{\left(N_{2}\right)^{3}}$ & -220.491687402358 \\
\hline$\alpha_{\left(N_{2}\right)^{4}}$ & 1419.68005396242 \\
\hline$\alpha_{\mathrm{CO}_{2}}$ & -953.460328339263 \\
\hline$\alpha_{\left(\mathrm{CO}_{2}\right)^{2}}$ & 1148.48725868228 \\
\hline$\alpha_{\left(\mathrm{CO}_{2}\right)^{3}}$ & -601.339855375907 \\
\hline$\alpha_{\left(\mathrm{CO}_{2}\right)^{4}}$ & 448.125565457084 \\
\hline$\alpha_{C O}$ & -5813.75996390021 \\
\hline$\alpha_{(\mathrm{CO})^{2}}$ & 5511.72102582867 \\
\hline$\alpha_{(\mathrm{CO})^{3}}$ & 1647.04306584326 \\
\hline$\alpha_{(\mathrm{CO})^{4}}$ & -3471.24152555425 \\
\hline$\alpha_{\mathrm{H}_{2}}$ & -906.859878136883 \\
\hline$\alpha_{\left(H_{2}\right)^{2}}$ & 1059.74781014028 \\
\hline$\alpha_{\left(H_{2}\right)^{3}}$ & -1302.86158149863 \\
\hline$\alpha_{\left(H_{2}\right)^{4}}$ & 3639.8594930452 \\
\hline$\beta_{\mathrm{CH}_{4} * \mathrm{C}_{2} \mathrm{H}_{6}}$ & 201.788909592169 \\
\hline$\beta_{\mathrm{CH}_{4} * \mathrm{C}_{3} \mathrm{H}_{8}}$ & -865.856657223225 \\
\hline$\beta_{C H_{4} * n-C_{4} H_{10}}$ & -1210.2275419324 \\
\hline$\beta_{\left(\mathrm{CH}_{4} * n-C_{4} H_{10}\right)^{2}}$ & 1331.55552369645 \\
\hline$\beta_{C_{4} * i-C_{4} H_{10}}$ & -1023.2781474703 \\
\hline$\beta_{\left(\mathrm{CH}_{4} * i-C_{4} H_{10}\right)^{2}}$ & 1550.09518461258 \\
\hline$\beta_{C_{4} * n-C_{5} H_{12}}$ & -2811.67740432523 \\
\hline$\beta_{C_{4} * i-C_{5} H_{12}}$ & 3363.98150506356 \\
\hline$\beta_{\mathrm{CH}_{4} * \text { neo- }-\mathrm{C}_{5} \mathrm{H}_{12}}$ & -1534.52567488723 \\
\hline$\beta_{\mathrm{CH}_{4} * N_{2}}$ & -1.053973329306 \\
\hline$\beta_{\mathrm{CH}_{4} * \mathrm{CO}_{2}}$ & 473.57476410971 \\
\hline
\end{tabular}

569.285536016002

$-650.8543394907$

64.359575257386

17.214959222054

$-645.099966662855$

694.229376857102

$-675.381075231165$

1474.79079137333

499.39849265152

$-576.665945472394$

252.19367406028

593.958975466507

934.46627322324

$-86.872357077024$

-20418.9067673979

633286.561358521

735.223884113728

$-3182.61439337967$

20945.1867250219

159067.868032595 


\begin{tabular}{|c|c|}
\hline Coefficient & Value \\
\hline$\beta\left(\mathrm{CH}_{4} * \mathrm{CO}_{2}\right)^{2}$ & -308.25901022921 \\
\hline$\beta_{\mathrm{CH}_{4} * \mathrm{CO}}$ & 5356.4335705495 \\
\hline$\beta_{\mathrm{CH}_{4} * \mathrm{H}_{2}}$ & 118.685621913274 \\
\hline$\beta_{\mathrm{CH}_{4} * \mathrm{H}_{2}^{2}}$ & 252.885168496247 \\
\hline$\beta_{\mathrm{CH}_{4}^{2} * \mathrm{H}_{2}}$ & 325.305174695724 \\
\hline$\beta_{C_{2} H_{6} * C_{3} H_{8}}$ & 0 \\
\hline$\beta_{C_{2} H_{6} * n-C_{4} H_{10}}$ & -437.695363730406 \\
\hline$\beta_{C_{2} H_{6} * i-C_{4} H_{10}}$ & -109.983789902769 \\
\hline$\beta_{C_{2} H_{6} * n-C_{5} H_{12}}$ & -1870.34746500563 \\
\hline$\beta_{C_{2} H_{6} * i-C_{5} H_{12}}$ & 3909.50906076245 \\
\hline$\beta_{C_{2} H_{6} * n e o-C_{5} H_{12}}$ & -886.578525827322 \\
\hline$\beta_{C_{2} H_{6} * N_{2}}$ & 968.887620927515 \\
\hline$\beta_{C_{2} H_{6}^{2} * N_{2}}$ & 267.47276619196 \\
\hline$\beta_{C_{2} H_{6} * N_{2}^{2}}$ & 337.464863958288 \\
\hline$\beta_{\mathrm{C}_{2} \mathrm{H}_{6} * \mathrm{CO}_{2}}$ & 1431.95011699315 \\
\hline$\beta_{\mathrm{C}_{2} \mathrm{H}_{6} * \mathrm{CO}}$ & 6463.14444295627 \\
\hline$\beta_{C_{2} H_{6} * H_{2}}$ & 1865.09090384357 \\
\hline$\beta_{C_{3} H_{8} * n-C_{4} H_{10}}$ & -118.490180710956 \\
\hline$\beta_{C_{3} H_{8} * i-C_{4} H_{10}}$ & 0 \\
\hline$\beta_{C_{3} H_{8} * n-C_{5} H_{12}}$ & -1734.80568239427 \\
\hline$\beta_{C_{3} H_{8} * n-C_{5} H_{12}^{2}}$ & 127551.642193201 \\
\hline$\beta_{C_{3} H_{8}^{2} * n-C_{5} H_{12}}$ & 11318.4183950722 \\
\hline$\beta_{C_{3} H_{8} * i-C_{5} H_{12}}$ & 3318.96820819338 \\
\hline$\beta_{C_{3} H_{8} * n e o-C_{5} H_{12}}$ & 0 \\
\hline$\beta_{C_{3} H_{8} * N_{2}}$ & 13.345337812469 \\
\hline$\beta_{C_{3} \mathrm{H}_{8} * \mathrm{CO}_{2}}$ & 292.275289330565 \\
\hline$\beta_{C_{3} H_{8} * \mathrm{CO}}$ & 5403.50260794829 \\
\hline$\beta_{C_{3} H_{8}^{2} * C O}$ & 2333.82346342921 \\
\hline$\beta_{C_{3} H_{8} * H_{2}}$ & 957.887281487301 \\
\hline$\beta_{n-C_{4} H_{10} * i-C_{4} H_{10}}$ & 3500.70282852274 \\
\hline$\beta_{n-C_{4} H_{10} * n-C_{5} H_{12}}$ & -4737.32849494999 \\
\hline$\beta_{n-C_{4} H_{10} * n-C_{5} H_{12}^{2}}$ & 525591.310711326 \\
\hline$\beta_{n-C_{4} H_{10}^{2} * n-C_{5} H_{12}}$ & 297556.039242685 \\
\hline$\beta_{n-C_{4} H_{10} * i-C_{5} H_{12}}$ & 6095.059988750870 \\
\hline$\beta_{n-C_{4} H_{10} * n e o-C_{5} H_{12}}$ & -953.002183779388 \\
\hline$\beta_{n-C_{4} H_{10} * N_{2}}$ & 0 \\
\hline$\beta_{n-\mathrm{C}_{4} \mathrm{H}_{10} * \mathrm{CO}_{2}}$ & -103.571484346062 \\
\hline$\beta_{n-C_{4} H_{10} * C O}$ & 5869.19050652774 \\
\hline$\beta_{n-C_{4} H_{10} * H_{2}}$ & 1267.61953483589 \\
\hline$\beta_{i-C_{4} H_{10} * n-C_{5} H_{12}}$ & 5056.60309163761 \\
\hline$\beta_{i-C_{4} H_{10} * i-C_{5} H_{12}}$ & 6619.27877637044 \\
\hline$\beta_{i-C_{4} H_{10} * n e o-C_{5} H_{12}}$ & -1363.96101644841 \\
\hline$\beta_{i-C_{4} H_{10} * N_{2}}$ & 14.803895799972 \\
\hline$\beta_{i-\mathrm{C}_{4} \mathrm{H}_{10} * \mathrm{CO}_{2}}$ & 211.752602673394 \\
\hline
\end{tabular}

\begin{tabular}{|c|c|}
\hline Coefficient & Value \\
\hline$\beta_{i-C_{4} H_{10} * C O}$ & 5786.32525717488 \\
\hline$\beta_{i-C_{4} H_{10} * H_{2}}$ & 1458.46072043154 \\
\hline$\beta_{n-C_{5} H_{12} * i-C_{5} H_{12}}$ & 12268.283772748 \\
\hline$\beta_{n-C_{5} H_{12}} * n e o-C_{5} H_{12}$ & 0 \\
\hline$\beta_{n-C_{5} H_{12} * N_{2}}$ & -1573.68893770625 \\
\hline$\beta_{n-C_{5} H_{12}} * \mathrm{CO}_{2}$ & -898.466856535774 \\
\hline$\beta_{n-C_{5} H_{12}^{2}} * \mathrm{CO}_{2}$ & -42401.4111391824 \\
\hline$\beta_{n-C_{5} H_{12}} * C O$ & 3985.11042051103 \\
\hline$\beta_{n-C_{5} H_{12}^{2}}^{2} * C O$ & 48265.3191033737 \\
\hline$\beta_{n-C_{5} H_{12} * H_{2}}$ & -1112.4435277056 \\
\hline$\beta_{n-C_{5} H_{12}^{2} * H_{2}}$ & 99558.3333419432 \\
\hline$\beta_{i-C_{5} H_{12} * n e o-C_{5} H_{12}}$ & 3773.44926785397 \\
\hline$\beta_{i-C_{5} H_{12} * N_{2}}$ & 4490.67830032675 \\
\hline$\beta_{i-C_{5} H_{12} * \mathrm{CO}_{2}}$ & 5122.00993545509 \\
\hline$\beta_{i-C_{5} H_{12}^{2} * \mathrm{CO}_{2}}$ & -28087.8481864326 \\
\hline$\beta_{i-C_{5} H_{12} * C O}$ & 10248.3408254232 \\
\hline$\beta_{i-C_{5} H_{12} * H_{2}}$ & 5464.93466923221 \\
\hline$\beta_{\text {neo- } C_{5} H_{12} * N_{2}}$ & -642.170828416611 \\
\hline$\beta_{n e o-C_{5} H_{12} * \mathrm{CO}_{2}}$ & 0 \\
\hline$\beta_{\text {neo- }-C_{5} H_{12}^{2}}^{2} * \mathrm{CO}_{2}$ & -11320.1126899481 \\
\hline$\beta_{n e o-C_{5} H_{12} * C O}$ & 4772.67730118682 \\
\hline$\beta_{\text {neo- } C_{5} H_{12^{*} H_{2}}}$ & 0 \\
\hline$\beta_{\mathrm{N}_{2} * \mathrm{CO}_{2}}$ & 1156.20032716021 \\
\hline$\beta_{\mathrm{N}_{2}^{2} * \mathrm{CO}_{2}}$ & 359.342203118816 \\
\hline$\beta_{N_{2} * \mathrm{CO}}$ & 6076.81809291631 \\
\hline$\beta_{N_{2}^{2} * C O}$ & 389.853153629781 \\
\hline$\beta_{N_{2} * \mathrm{CO}^{2}}$ & 367.319351280689 \\
\hline$\beta_{N_{2} * H_{2}}$ & 1506.65564191457 \\
\hline$\beta_{\mathrm{CO}_{2} * \mathrm{CO}}$ & 6557.3763494187 \\
\hline$\beta_{\left(\mathrm{CO}_{2} * \mathrm{CO}\right)^{2}}$ & 1824.58587937403 \\
\hline$\beta_{\mathrm{CO}_{2} * \mathrm{H}_{2}}$ & 1924.91759508054 \\
\hline$\beta_{\left(\mathrm{CO}_{2} * \mathrm{H}_{2}\right)^{2}}$ & -1656.21974526347 \\
\hline$\beta_{\mathrm{CO} * \mathrm{H}_{2}}$ & 6896.45838807018 \\
\hline$\left.\beta_{(\mathrm{CO}} * \mathrm{H}_{2}\right)^{2}$ & 911.791848875967 \\
\hline
\end{tabular}

\section{References}

[1] J. B. Heywood., International Combustion Engine fundamentals, McGraw-Hill, 1989.

[2] M. Leiker, W. Cartelliere, H. Christoph, U. Pfeifer, M. Rankl,, "Evaluation of Anti-Knock Property of Gaseous Fuels by Means of the Methane Number and Its Practical Application", ASME paper 72-DGP-4, April 1972.

[3] California Alternative Fuels for Motor Vehicle Regulations Appendix D: Methane Number and fuel composition, https://www.arb.ca.gov/regact/cng-lpg/appd.pdf 
[4] Gary Choquette, "Analysis and estimation of stoichiometric air-fuel ratio and methane number for natural gas", 23rd Gas Machinery Conference, Nashville, USA, October 5-8, 2014.

[5] G. W. Sorge, R. J. Kakoczki, and J. E. Peffer, "Method for determining knock resistance rating for non-commercial grade natural gas", US Patent 6,061,637, May 9, 2000.

[6] R. T. Smith, G. W. Sorge, and J. R. Zurlo, "Systems and Methods for Engine Control Incorporating Fuel Properties", European Patent EP 2963270 A1, 25th May 2015.

[7] EN16726: 2014 - Annex A.

[8] C. Rahmouni, G. Brecq, M. Tazerout, O. Le Corre, (2004) Knock rating of gaseous fuels in single cylinder spark ignition engine, Fuel 83 (3) 327-336.

[9] "Gas Methane Number Calculation MWM method", April 2013 (documentation Euromot MWM tool).

[10] Methane number calculation of natural gas mixtures, http://mz.dgc.eu./

[11] http://www.cumminswestport.com/fuel-quality-calculator

[12] https://www.wartsila.com/products/marine-oil-gas/gas-solutio ns/methane-number-calculator

[13] https://www.dnvgl.com/oilgas/natural-gas/fitness-for-purposeof-lng-pki-methane-number-calculator.html

[14] https://www.dnvgl.com/oilgas/natural-gas/fitness-for-purposefor-pipeline-gas.html

[15] GasCalc Software, http://www.eon.com/en/business-areas/technical-sercices/gasc alc-software.html

[16] EUROMOT position paper, "Methane number as a parameter for gas quality specifications", 2012.
[17] Callahan, T. J., Ryan III, T. W., Buckingham, J. P., Kakockzi, R. J. and Sorge, G., ICE-Vol. 27-4, 1996, Fall Technical Conference Vol. 4, pp. 59-64, ASME.

[18] Gersen, S., Essen, M., Levinsky, H., and Dijk, G., "Characterizing Gaseous Fuels for Their Knock Resistance based on the Chemical and Physical Properties of the Fuel," SAE Int. J. Fuels Lubr. 9 (1): 1-13, 2016, doi: 10.4271/2015-01-9077.

[19] G. van Dijk, M. van Essen and S. Gersen, "A Feed-Forward Fuel-Adaptive Gas Engine Control Approach Based on a Knock-Prediction Algorithm”, $17^{\text {th }}$ Conference „The Working Process of the Internal Combustion Engine", Graz, Austria, September 26-27, 2019.

[20] K. Portin and D. Högberg, "Gas Online Quality Measurement for Optimized Engine Control”, CIMAC, paper no. 109, 2019.

[21] Martijn Van Essen, Sander Gersen, Gerco Van Dijk, Maurice Van Erp, En Howard Levinsky. Algorithm for Determining the Knock Resistance of LNG. International Journal of Energy and Power Engineering. Vol. 8, No. 2, 2019, pp. 18-27. doi: 10.11648/j.ijepe.20190802.12.

[22] S. Gersen, M. van Essen, H. Darmeveil, H. Hashemi, C. T. Rasmussen, J. M. Christensen and P. Glarborg, "Experimental and Modeling Investigation of the Effect of $\mathrm{H}_{2} \mathrm{~S}$ Addition to Methane on the Ignition and Oxidation at High Pressure", Energy Fuels 2017, 31, 2175-2182, DOI: 10.1021/acs.energyfuels.6b02140.

[23] Essen, M., Gersen, S., Dijk, G., Mundt, T. et al., "The Effect of Humidity on the Knock Behavior in a Medium BMEP Lean-Burn High-Speed Gas Engine," SAE Int. J. Fuels Lubr. 9 (3): 2016, doi: 10.4271/2016-01-9075.

[24] Martijn van Essen, Sander Gersen, Gerco van Dijk, Liming Dai, Howard Levinsky, Peter van Wesenbeeck, "The knock propensity of $\mathrm{CO}_{2}$ containing natural gases", SAE paper, to be submitted. 